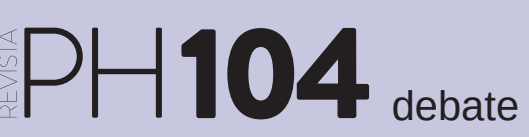

a debate Patrimonio cultural y cambio climático

| coordina Alejandro García Hermida

\title{
Arquitectura tradicional y sostenibilidad. Arquitectura industrial e insostenibilidad
}

Jaime de Hoz Onrubia | Área de Composición Arquitectónica, Universidad Alfonso X el Sabio

URL de la contribución <www.iaph.es/revistaph/index.php/revistaph/article/view/4984>

Frente a la arquitectura que figura en los libros de historia del arte, la denominada "monumental", "culta" o "intelectual", estudiada y aprendida en las escuelas de arquitectura, vinculada siempre a la idea de "estilo" y generalmente a una autoría con frecuencia precisa, podemos establecer otros conceptos edificatorios, marginales en su observación académica, y casi siempre ajenos a las obras de referencia, como son los de construcción "popular" y arquitecturas tradicional y vernácula. Han sido estas formas constructivas, sin embargo, las habituales en el devenir de la civilización, pues se vinculan directamente con el espacio de habitación de las gentes, su forma de vida y sus costumbres cotidianas. Las define el aprovechamiento máximo de los recursos naturales, empleando como materiales de construcción aquellos que el medio cercano ha podido proporcionarles sin tener que hacer grandes esfuerzos para obtenerlos (piedra, madera, tierra...). Las distingue, así mismo, la austeridad económica, pero no necesariamente la miseria, implicando al propio usuario en su creación, lo que da prioridad en ellas a la experiencia devenida de las numerosas generaciones que han habitado el mismo territorio durante largos siglos, posibilitando su perfecta adaptación, empírica y pragmática, al medio, que les proporciona una enorme eficacia energética, pensando prioritariamente en el beneficio del usuario.

La arquitectura que llamamos "tradicional" es, pues, el resultado de un largo proceso de adaptación. Se transmite de generación en generación, aportando el conocimiento de las nuevas experiencias, y se va readecuando a procesos de cambio que han sido siempre lentos y dilatados en el tiempo. Su apariencia ha resultado casi imperturbable y las técnicas con las que se ha realizado su edificación nunca han sido ni traumáticas ni agresivas con su medio físico. La escasa mutabilidad es una de sus principales características y ello ha hecho que el cromatismo de los materiales empleados, las formas de sus cubiertas y la textura de sus muros hayan contribuido a proporcionar los rasgos exclusivos y peculiares, "vernáculos", de los edificios propios de una determinada región o de un lugar concreto. Así, la arquitectura tradicional se compenetra con el paisaje de su entorno, condicionado antrópicamente y asociado, al igual que las casas y las otras construcciones, a la economía local y a sus condiciones climáticas, a su vegetación, a su tipo de suelo...

Contradictoriamente con lo que después ha terminado sucediendo, contribuyendo a su desaparición o a su deterioro, los primeros arquitectos del llamado movimiento moderno ensalzaron sus virtudes arquitectónicas y sus valores estéticos, incluso usándolas como referente para sus novedosas propuestas. De este modo Adolf Loos elogiaba y reclamaba estos edificios como parte del paisaje natural y aplaudía su sobria belleza: "No parecen creados por la mano del hombre. Están como recién salidos del taller de Dios, como las montañas y los árboles, las nubes y el cielo. Y todo respira belleza y silencio [...]" (Architektur, publicado en la revista Der Sturm el 15 de diciembre de 1910). El problema devino de la absoluta falta de conocimiento real que los vanguardistas arquitectos tenían sobre la razón constructiva de estas edificaciones, desdeñando su auténtico valor funcional o el sentido ecológico con el que se concebían, quedando toda observación en una mera banalización snob de su estética o en una reducción trivializada de su realidad, lo que ha ido generando horribles monstruos seudorrurales o falsamente vernáculos, como las viviendas "recreadas" por artistas inspirados, caso de César Manrique en Lanzarote, quien terminó por implantar un modelo ibicenco donde la realidad era bastante 


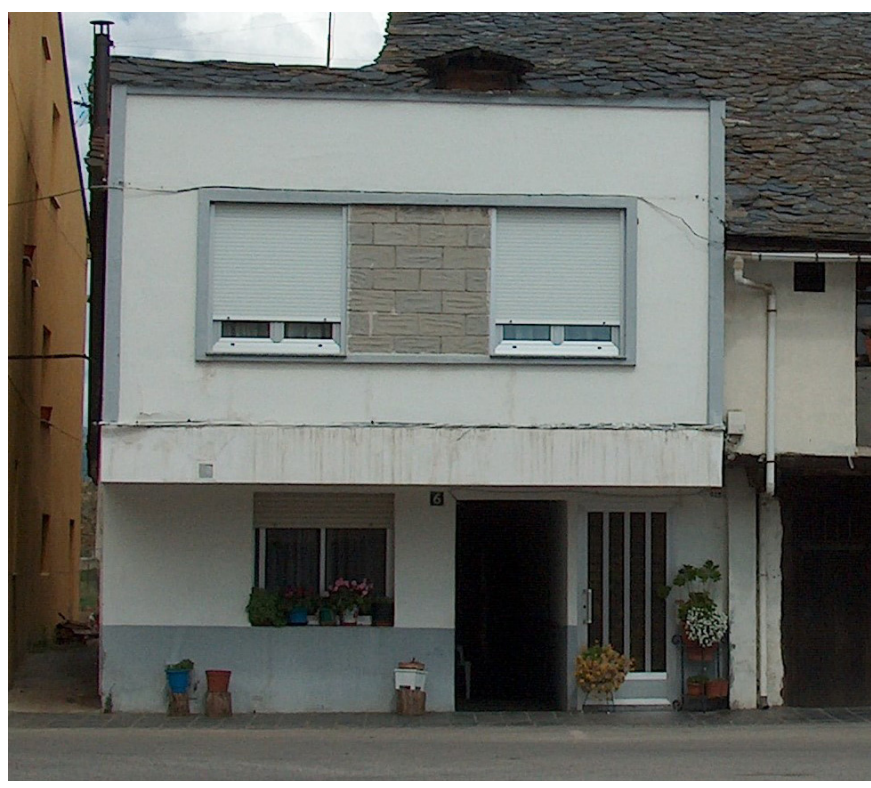

Adición modernizada según los patrones indicados por la "doctrina" de las Escuelas de Arquitectura en Cacabelos (León) | foto Jaime de Hoz Onrubia

diferente, aniquilando la auténtica huella de los edificios tradicionales de esta isla, a los que supuestamente pretendía enaltecer y a los que se ha terminado, prácticamente, por hacer desaparecer, no siendo todo ello sino el resultado de una reprobable falta de estudio por parte de la mayoría de los arquitectos contemporáneos, por no hablar de los intereses de constructores y fabricantes de cemento y hormigón, y por supuesto por una actitud no siempre socialmente conveniente de los políticos ni de los responsables del patrimonio.

Esta falta de criterio ha generado la imposición doctrinal desde las Escuelas de Arquitectura de un modelo "mediterráneo" de vivienda, siempre de forma cúbica, con cubierta plana y huecos distribuidos aleatoriamente por las fachadas sin haber comprendido su gnosis lógica y su obligada adaptación a cada territorio particular, sin importarles la orientación, el clima o el índice de pluviosidad o de soleamiento del sitio en el que se han de erigir sus "creativas" indecencias, arrasando toda forma de arquitectura que no respondiese a sus principios doctrinales e incuestionables dogmas de fe, como los dictados por las ocurrencias del "mesías" Le Corbusier, quien ni era arquitecto ni tenía una formación académica y artesanal adecuadas, generando de tal guisa auténticas aberraciones en toda nuestra geografía, sólo para saciar el muy cuestionable gusto de ignaros acomplejados y de gentes ávidas de ganancias fáciles, donde por desgracia hay que incluir a religiosos y destacados docentes.

Tal banalización ha tenido, igualmente, una consecuencia funesta para la habitabilidad de las personas, pues a menudo se les obliga a vivir en esculturas gigantes y no en espacios adecuados, reduciendo lo arquitectónico a un mero referente "estético", aunque con frecuencia se ignore de dónde procede y lo que significa aquello que Vitrubio denominaba venustas, por lo que todo ha derivado en una suerte de "estética y descomposición". El resultado último es el consumo excesivo de energía para refrigerar unas casas inadaptadas de por sí al lugar o unos gastos insoportables para calefactarlas. Los tan traídos ejemplos de la Villa Saboya o de la casa Farnsworth son de notorio conocimiento, sirviendo, desgraciadamente, de modelo para los estudiantes y de referencia imperativa para la vivienda unifamiliar, si bien nunca explicándoseles a aquéllos la incapacidad de tales "gloriosos" ejemplos para ser vividos, la ruina que supusieron para sus propietarios y las numerosas y costosas restauraciones y reconstrucciones que se han tenido que operar en ellos para mero disfrute de algunos intelectos vivificados por la "modernidad".

La mala comprensión del funcionamiento de este patrimonio arquitectónico, y aun urbano (fondos de saco, pozos de ventilación, etc.), devenido de la tradición, substituido por formas "actualizadas", ha conllevado el empleo de materiales industriales, cuyo rendimiento no es ni mucho menos el mismo que el empleado por aquellas construcciones heredadas (inercia térmica, aislamiento pasivo, transpiración...), pues al no atender a la orientación, abrir huecos excesivamente grandes o no respetar los estándares de muros y cubiertas obliga, como consecuencia, a un consumo de energía que indudablemente provoca una mayor contaminación medioambiental, la cual contribuye a generar condiciones apropiadas para un cambio climático. 